\title{
Development of new methods for increasing the germination of licorice (Glycyrrhiza uralensis Fisch.) seeds: preliminary data
}

\author{
Nikolai Kruglikov ${ }^{1, *}$, Andrey Bystrushkin ${ }^{2}$, and Alexander Belyaev ${ }^{3}$ \\ ${ }^{1}$ M.N. Mikheev Institute of Metal Physics of the Ural Branch of the Russian Academy of Sciences, \\ laboratory of strength, 620108 Yekaterinburg, Russia \\ ${ }^{2}$ Institute Botanic Garden Ural Branch of Russian Academy of Sciences, laboratory of experimental \\ ecology and plants acclimatization, 620144 Yekaterinburg, Russia \\ ${ }^{3}$ Institute of Plant and Animal Ecology, Ural Branch, Russian Academy of Sciences, laboratory of \\ plant molecular ecology, 620144 Yekaterinburg, Russia
}

\begin{abstract}
The licorice (Glycyrrhiza uralensis Fisch.) is cultivated as a valuable medicinal plant. It is grown from seeds, but $70-90 \%$ of its seeds are in deep physical dormancy (hard seeds) - do not swell and do not germinate without special treatment (scarification). We are searching for the most effective methods of such processing. We have studied the effect of hydrostatic pressure from 10 to $40 \mathrm{MPa}$ (pressure treatment) on the licorice seeds to improve the swelling and germination of them, which belong to a pair of visually distinguished groups by the color of the seed coat. For the first time, it was found that olive-colored seeds do not germinate after pressure treatment (the number of hard seeds is $80 \%$ or more). At the same time, very high content (up to $90 \%$ ) of swollen but non-viable seeds was detected in the group with a light brown color of the seed coat. Hydrostatic pressure levels used did not significantly reduce hard seeds proportion in studied licorice seed material. A weak positive effect of hydrostatic pressure treatment was found. Further search for optimal pressure treatment modes for licorice seeds germination increasing looks promising.
\end{abstract}

\section{Introduction}

Licorice (Glycyrrhiza uralensis Fisch.) is known in Russia, Kazakhstan, China, and other Asian countries as a particularly valuable medicinal, technical, and food plant [1, 2]. The raw material is the roots and rhizomes of licorice - the so-called "licorice root". The worldwide demand for this resource is tens of thousands of tons (in combination with raw of other pharmacopoeia licorice species, and in terms of air-dry mass). Due to large-scale anthropogenic transformations of natural ecosystems and abnormal harvesting of licorice root, the reserves of this raw material in natural plant communities are steadily decreasing. To solve this resource problem, it is necessary to create industrial licorice plantations [3].

\footnotetext{
* Corresponding author: nick@imp.uran.ru
} 
Experiments on the cultivation of licorice in the republics of the former USSR, started in the 1960 s, were successful.

Discussed species of licorice by the end of the third and fourth growing seasons in conditions of fully mechanized field experiments on large areas as in crops on small experimental plots formed a yield of underground organs similar to the reserves of licorice root in natural thickets. This allows us to consider Glycyrrhiza uralensis as a promising agricultural crop suitable for growing even on saline lands. Cultivation from seeds is recognized as most promising technology for creation of industrial licorice plantations. In this case rather high seed rates are indicated $-6-12 \mathrm{~kg} / \mathrm{ha}$. Harvesting of licorice seeds in large quantities is quite possible in some southern regions of the Asian part of Russia, in the Republic of Kazakhstan. However, significant difficulties are associated with pre-sowing seed preparation $[4,5]$.

Seeds of most species of natural flora legumes, including the licorice, are characterized by deep physical dormancy. Seeds with this property are called hard seeds. Due to the special structure their seed coat is impermeable to water. Such seeds do not swell and do not germinate even under the most favorable humidity and temperature [6, 7]. After breaking the waterproofing of the seed coat by mechanical methods, thermal effects, or when treated with sulfuric acid, hard seeds mostly germinate normally $[6,8]$.

The fraction of hard seeds in the seed material of G. uralensis can reach 70-90\% $[5,9]$. To significantly increase the laboratory and field germination of the seeds, various methods were used, including scarification of seeds with sandpaper, serial immersions of seeds in boiling and cold water, and treatment with concentrated sulfuric acid [4, 10, 11]. But agronomic practice is needed to further searching for optimal variants of pre-sowing treatment of licorice seeds. The authors of this work proposed a new promising method of pre-sowing seed treatment - pressure treatment. That is the effect of certain level hydrostatic pressure on the seeds [12]. Our study is aimed at searching for modes of pressure treatment that help overcome hardseededness in licorice, which is especially important for pre-sowing (and therefore pre-sale) preparation of large quantities of seeds necessary for the creation of industrial licorice plantations. The purpose of our work: to study the effects of hydrostatic pressure (pressure treatment) on the licorice ( $G$. uralensis) seeds in various modes to justify and implement new methods for hard seeds dormancy overcoming.

\section{Materials and methods}

The licorice seeds used in this study were collected in 2012 in a local population near Karaganda (Republic of Kazakhstan). Cleaning of these seeds from bean leaves, puny and damaged seeds were carried out manually without the use of any grating devices in order to preserve the seed cover (seed coat) in its natural state. Prepared for experiments initial seed sample consisted of completed and intact (by appearance) seeds. It was visually divided into two groups (fractions) that differ in the colour of the seed coat - olive and light brown, and the study was conducted with them. The characterization of the groups is described in our previous paper [9]. Seeds of both fractions were subjected to hydrostatic pressure (according to the experiment variants) and their subsequent germination was carried out when they were placed together in pressure chambers and Petri dishes according to each experiment variant and replication.

A laboratory hydrostat filled with industrial oil with an operating volume of 5 liters and a working pressure of up to $250 \mathrm{MPa}$ was used for processing seeds with a pressure of 10 to $40 \mathrm{MPa}$ [13]. The cylinder-piston system of the original design was used for direct processing of seeds in an aquatic environment. Three types of seed pressure treatment and one reference group (without pressure treatment) were used, each in three-fold replication. 
The first experiment type is a single treatment of seeds with a pressure of $10 \mathrm{MPa}$. The second is a three-time treatment of seeds with a pressure of $10 \mathrm{MPa}$. The third is a single treatment of seeds with a pressure of $40 \mathrm{MPa}$. Due to the limited number of completed (full-fledged) seeds in the initial sample and a significant disparity in the content of seeds of different colours in the samples, the number of seeds of different colours in replications for different types of the experiment also varied. However, the total sample size in each experimental variant was 150 seeds, and the total number of seeds of different colours in the corresponding replications was 50 . This allowed us to perform correct data processing. In the reference variant, 100 seeds were studied without pressure treatment, the replications for two groups of seeds of different colours contained: olive seeds - 24, 24, 25 PCs., light brown seeds - 9, 9, 9 PCs. Respectively, the co-germinated samples contained 33, 33, and 34 seeds.

In accordance with the previously tested method [9], seed germination was performed on wet filter paper in Petri dishes in a Binder climate chamber at a constant temperature of $30^{\circ} \mathrm{C}$ in the dark. The proportion of swollen and sprouted seeds was taken into account after ten days. The difference between the experimental and reference variants was studied using the analysis of variance (ANOVA). We used common significance level of statistical criteria for biological objects $(\mathrm{p}=0.05)$.

\section{Results and Discussion}

The table shows data on the percentage of swollen and sprouted seeds in the variants of the experiment with licorice seeds of two groups that differ in the color of the seed coat.

Table 1. Swelling and germination of licorice seeds in two color groups after pressure treatment in different modes

\begin{tabular}{|l|c|c|c|c|c|c|}
\hline \multirow{2}{*}{$\begin{array}{l}\text { Pressure treatment } \\
\text { variant }\end{array}$} & \multicolumn{2}{|c|}{ Number of seeds } & \multicolumn{2}{c|}{$\begin{array}{c}\text { Percentage of swollen } \\
\text { seeds* }\end{array}$} & \multicolumn{2}{c|}{$\begin{array}{c}\text { Percentage of sprouted } \\
\text { seeds }\end{array}$} \\
\cline { 2 - 7 } & Olive & $\begin{array}{c}\text { Light } \\
\text { brown }\end{array}$ & Olive & Light brown & Olive & $\begin{array}{c}\text { Light } \\
\text { brown }\end{array}$ \\
\hline $\begin{array}{l}\text { Single pressure } \\
\text { treatment 10 MPa }\end{array}$ & 108 & 42 & $\begin{array}{c}6,5 \\
(2,6-12,5)\end{array}$ & $\begin{array}{c}71,4 \\
(41,7-88,9)\end{array}$ & $\begin{array}{c}1,9 \\
(0-3,1)\end{array}$ & 0 \\
\hline $\begin{array}{l}\text { Triple pressure } \\
\text { treatment 10 MPa }\end{array}$ & 118 & 32 & $\begin{array}{c}12,7 \\
(11,9-13,9)\end{array}$ & $\begin{array}{c}78,1 \\
(71,4-87,5)\end{array}$ & $\begin{array}{c}3,4 \\
(0-8,3)\end{array}$ & 0 \\
\hline $\begin{array}{l}\text { Single pressure } \\
\text { treatment 40 MPa }\end{array}$ & 119 & 31 & $\begin{array}{c}8,4 \\
(4,7-11,9)\end{array}$ & $\begin{array}{c}71,0 \\
(50,0-81,3)\end{array}$ & $\begin{array}{c}0,8 \\
(0-2,9)\end{array}$ & 0 \\
\hline $\begin{array}{l}\text { Reference } \\
\text { (without } \\
\text { treatment) }\end{array}$ & 73 & 27 & $\begin{array}{c}8,2 \\
(0-12,5)\end{array}$ & $\begin{array}{c}88,9 \\
(77,8-100)\end{array}$ & 0 & 3,7 \\
& & & $0-11,1)$ \\
\hline
\end{tabular}

*The average percentage values are shown and deviation limits among replications are shown in parentheses.

Swollen seeds are detected within the first day of the experiment after setting the studied seed samples for germination. Accounting for the number of swollen seeds in groups with different color of the seed coat after ten days of the experiment showed that in all variants of pressure treatment and in the reference variant, the proportion of swollen seeds in the light brown group is 5-10 times greater than in the group of olive-colored seeds. When analyzing the data for this indicator, it was found that the proportion of variance due to differences in seed colour is $55.7 \%$. The effect of this factor on seed swelling is statistically significant $F(1 ; 0.001)=23.11$. The fraction of variance explained by differences in the methods of pressure treatment of seeds is $1.5 \%$, and there are no 
statistically significant differences between the variants of the experiment for the considered indicator, $\mathrm{F}(3 ; 0.89)=0.21$. The interaction of seed colour factors and the method of pressure treatment accounts for $4.2 \%$ of the total variance, the interaction of factors is not statistically significant, $F(3 ; 0.64)=0.57$. Value of variance equal to $38.6 \%$ is accounted for by random factors that are not controlled in the experiment.

Thus, the olive and light brown seeds of licorice in the studied sample from Kazakhstan differ significantly in their ability to swell under standard germination conditions, and this difference persists after applying different modes of pressure treatment. This is due to the very high content (predominance) of hard seeds in the group with olive-colored seed coats, as well as the fact that the levels and modes of hydrostatic pressure used in the experiment do not lead to a significant destruction of the waterproofness of the seed coats in the group of olive-colored seeds.

Seed germination under the mode set in the climate chamber began on the third day of the experiment and reached the plateau on the eighth day. When accounting for sprouted seeds after ten days, it was found that olive-coloured seeds germinated in small quantities in all experimental groups with pressure treatment, and in the reference group there was no germination. In the group of light-brown seeds, germination was observed only in the control group without pressure treatment (see the table). These data allow us to suggest that the pressure treatment of licorice seeds at relatively low levels of hydrostatic pressure (10$40 \mathrm{MPa}$ ) can damage certain parts of the seed cover of small part of hard seeds (as previously found [9], they predominate in the olive fraction) creating conditions for water penetration.

The complete absence of germination of light brown seeds after pressure treatment may indicate that the few seeds that are able to germinate contained in this fraction are significantly damaged and lose their viability. Taking into account the experience of other studies aimed at developing methods for overcoming hard-seeding in legumes $[6,8]$, we consider the results of our work as preliminary, showing the possible prospects of hydrostatic pressure on solid licorice seeds to increase their germination. It is possible that in combination with any thermal effects, pressure treatment will provide a significant increase in the germination of licorice seeds.

\section{Conclusions}

1. The proportion of swollen seeds in the light brown group was 5-10 times higher than in the olive-colored group in all variants of pressure treatment and in the reference variant under standard germination conditions. This indicates the predominance of hard seeds in the group with olive-colored seed coats and their high resistance to applied hydrostatic pressure levels.

2. Exposure of licorice (G. uralensis) seeds to hydrostatic pressure in the range of 10-40 MPa did not significantly reduce the proportion of solid seeds in the test sample. However, only after pressure treatment, small number of olive-colored seeds germination indicates the presence of a positive influence of this effect - the water permeability of hard seed coats increases.

\section{Acknowledgments}

The work was partially supported by the RFBR: project No. 18-016-00082, as well as partially supported by Government order for the Institute Botanic Garden Ural Branch of Russian Academy of Sciences. 


\section{References}

1. G.P. Yakovlev, A.K. Sytin, Y.R. Roskov, Legumes of North Eurasia (Kew: Royal Botanical Gardens, 1996)

2. J.-T. Zhang, B. Xu, M. Li. J. Med. Plants Res, 4, 830 (2010) https://doi.org/10.5897/JMPR10.127

3. A.G. Tolstikov, L.A. Baltina, V.P. Grankina, R. M. Kondratenko, T. G. Tolstikova. Solodka: bioraznoobrazie, khimiya, primenenie $v$ meditsine (Licorice: biodiversity, chemistry, medical applications), (Novosibirsk: Geo, 2007) (in Russian)

4. E.B. Khudaibergenov, Licorice of Kazakhstan (Alma-Ata: Nauka Publ., 1979) (in Russian)

5. V.P. Grankina, T.P. Nadezhina, Ural licorice (Novosibirsk: Nauka Publ., 1991) (in Russian).

6. M.G. Nikolaeva, M.V. Razumova, V.N. Gladkova, Reference book on dormant seed germination (Leningrad: Nauka, 1985) (in Russian)

7. J.M. Baskin, C.C. Baskin, X.Li. Plant Species Biology, 15, 139 (2000)

8. M.A.I. Yousif, Y.R. Wang, X.W. Hu. Seed Science and Technology, 47, 131 (2019) https://doi.org/10.15258/sst.2019.47.2.02

9. A.G. Bystrushkin, N.A. Kruglikov, A.U. Belyaev, Bulletin of Botanic Garden of Saratov State University, 17, 185 (2019) (in Russian) DOI: 10.18500/1682-1637-20194-185-198

10. E.B. Khudaibergenov, V.P. Mikhailova, Rastitelnye resursy, 8, 225 (1972) (In Russian)

11. I.V. Shilova, T.Yu. Gladilina, E.P. Gorlanova, Bulletin of Botanic Garden of Saratov State University, 8, 199 (2009) (in Russian)

12. N.A. Kruglikov, A.G. Bystrushkin, I.N. Lespukh, L.N. Kruglikova, Green journal Bulletin of the Botanical Garden of Tver State University, 5, 14 (2018) (in Russian)

13. Yu.N. Loginov, B.I. Kamenetski, D.K. Bulychev, Patent № 95992. USSR. Bulletin, 35, 3 (1982) (in Russian) 